\title{
Estabilidad, profesionalismo y politización en los nombramientos de directivos de agencias reguladoras independientes: lecciones desde la experiencia chilena ${ }^{* * * * * * * * * *}$
}

\section{Stability, Professionalism and Politicization in the Appointment of the Heads of Independent Regulatory Agencies: Lessons from the Chilean Experience}

RESUMEN

Los autores comparan los nombramientos de los directivos de agencias reguladoras donde participó el Senado chileno con aquellos realizados discrecionalmente por el presidente, o bien a través del sistema de Alta Dirección Pública, i.e., un proceso de nombramiento que busca reconciliar la necesidad de estimular nombramientos de directivos con altas credenciales técnicas, con los intereses políticos del gobierno incumbente. El análisis de 200 nombramientos realizados entre 1990 y 2016 sugiere que los directivos elegidos con participación del Senado tienen niveles similares de afiliación política, pero mejores antecedentes profesionales respecto de las autoridades nombradas bajo los otros modelos institucionales. La evidencia también sugiere que el tiempo de permanencia de los directivos nombrados con par-

Doctor y magíster en Derecho, Universidad de California, Berkeley. Profesor del Departamento de Derecho Económico, Facultad de Derecho, Universidad de Chile (Chile). Correo electrónico: dpardow@derecho.uchile.cl. oRCiD: https://orcid.org/0000-0001-6537-4378

** Doctor en Derecho, Universidad de Nueva York (NYU) y magíster en Derecho, Universidad de California, Berkeley. Profesor de Derecho Constitucional, Universidad del Desarrollo (Chile). Correo electrónico: sverdugor@udd.cl. orCiD: https://orcid.org/0000-0002-9232-0786

*** Recibido el 30 de octubre del 2018, aprobado el 28 de enero del 2020.

Para citar el artículo: PARDOw D. y Verdugo S. Estabilidad, profesionalismo y politización en los nombramientos de directivos de agencias reguladoras independientes: lecciones desde la experiencia chilena. En Revista Derecho del Estado, Universidad Externado de Colombia. N. ${ }^{\circ} 46$, mayo-agosto de 2020, pp. 223-252.

DOI: https://doi.org/10.18601/01229893.n46.09

***** Esta investigación recibió financiamiento del Fondo Nacional de Desarrollo Científico y Tecnológico de Chile (FONDECYT, Proyecto No. 11150181). 
ticipación del Senado es dos veces más largo, mientras que casi tres veces más probable que se mantengan en sus cargos después de la instalación de un nuevo gobierno. Los datos también proporcionan evidencia útil para la discusión sobre el impacto que tienen los modelos de nombramiento sobre la autonomía de dichas instituciones. Existe un grado de correlación significativo entre la independencia formal y material de las agencias reguladoras chilenas, así como también la importancia del Senado en el sistema de frenos y contrapesos para los nombramientos directivos.

PALABRAS CLAVE

Agencias reguladoras, independencia formal, diseño institucional, control parlamentario, frenos y contrapesos.

\section{ABSTRACT}

The authors compare the appointments of the heads of regulatory agencies made with the participation of the Senate with those made either discretionally by the President, or through the system of High Public Directorship, i.e., an appointing procedure that seeks to reconcile the need to stimulate appointments of candidates with strong technical credentials, with the political interests of the incumbent government. The analysis of near 200 appointments made in Chile between 1990 and 2016, shows that the heads of regulatory agencies chosen with the involvement of the Senate have similar levels of political affiliation, but better overall professional credentials compared to the results achieved by other institutional models. Our evidence also suggests that the tenure of those officers is two times longer, and it is three times more likely that they remain in office after the installation of a new government. The article provides useful evidence to advance the discussion about the impact of the institutional appointing models on the autonomy of those institutions. There is a significant correlation between formal and material independence of Chilean regulatory agencies, as well as showing the importance of the Senate in the system of check and balances for appointing regulators.

KEYWORDS

Regulatory agencies, Formal independence, Institutional design, Parliament control, Check and balances.

SUMARIO

Introducción. 1. El rol del Senado y el debate sobre la autonomía. 2. Cuatro Modelos de Nombramiento. 3. Comparando el Desempeño Relativo. Conclusiones. Referencias. 
INTRODUCCIÓN

En Latinoamérica, las Agencias Reguladoras Independientes han recibido relativamente poca atención por parte de la literatura empírica, pese a que países como México y Colombia han mostrado esfuerzos por mejorar la autonomía de sus agencias reguladoras durante sus respectivos procesos de admisión a la OCDE. Es sabido que la creación y evolución de dichas agencias se ha asociado con el tránsito desde un Estado que participa en la economía produciendo bienes y servicios, hacia uno que solamente interviene regulando la actividad de empresas privadas ${ }^{1}$. Algunos estudios han contribuido a comprender y categorizar dichas instituciones, distinguiendo sus aspectos institucionales relevantes y examinando sus lógicas reguladoras ${ }^{2}$. Pero todavía sabemos poco acerca del funcionamiento real de estas agencias, especialmente a la hora de discernir si los incentivos institucionales operan de la manera prevista por la teoría. Ello se debe a que los estudios empíricos son todavía escasos. La literatura latinoamericana contemporánea ha estudiado, por ejemplo, la influencia que ejercen los gobiernos incumbentes respecto de agencias especializadas en área particular ${ }^{3}$, la manera en que han evolucionado ciertos diseños institucionales formales ${ }^{4}, \mathrm{o}$ los factores que podrían explicar la

1 El concepto de regulación económica tiende a estar asociado a los procesos de privatizaciones y reforma del Estado que se llevaron a cabo hacia finales del siglo pasado, especialmente en el Reino Unido y Estados Unidos, siguiendo un enfoque que suele conocerse como new public management. Moran, M. (2003). The British regulatory state: high modernism and hyper-innovation. Nueva York, Oxford University Press. Desde esta perspectiva, la idea de agencias reguladoras se relaciona con la capacidad del Estado para regular el funcionamiento de las empresas privadas en aquellos mercados donde previamente funcionaban monopolios de propiedad pública, tales como los servicios de salud, transporte, electricidad o telefonía. Con posterioridad, sin embargo, esta noción se extiende a la generalidad de los organismos que tienen una influencia directa en el funcionamiento de los mercados, con independencia de que hubiesen sido creado mucho antes de la década de los ochenta (v.g. bancos centrales, autoridades tributarias), o bastante tiempo después (v.g. protección al consumidor financiero). Ver Tucker, P. Unelected Power: The Quest for Legitimacy in Central Banking and the Regulatory State. Princeton University Press, 2018.

2 Un trabajo muy influyente que utiliza esta perspectiva es el de Guasch, J., y SPILLER, P. Managing the regulatory process: design, concepts, issues, and the Latin America and Caribbean story. The World Bank, 1999.

3 Por ejemplo, Murillo y Martínez se enfocan en los resultados de agencias en el área eléctrica, sugiriendo que la ideología de la coalición gobernante juega un rol relevante en dichos resultados. Martínez-Gallardo C. y Murillo MV. Agency under Constraint: Ideological Preferences and the Politics of Electricity Regulation in Latin America. Regulation \& Governance. 5, 2011: 350-367.

4 Un buen ejemplo de este tipo de estudio es el trabajo de Gutiérrez, quien distingue aspectos institucionales de agencias pertenecientes a 25 países latinoamericanos, en el sector de telecomunicaciones. GutiérREZ, LH. Regulatory Governance in the Latin American Telecommunications Sector. Utilities Policy. 11, 2003: 225-240. 
independencia formal de dichas instituciones ${ }^{5}$. La mayoría de estos estudios solo se enfocan en reguladores específicos y sus resultados son muchas veces limitados ${ }^{6}$. Una excepción a lo anterior es el trabajo de Pavón, quien analizó la variación en los niveles de independencia formal de agencias reguladoras de ocho países de la región y pone a prueba las tesis tradicionales acerca del nacimiento de las agencias reguladoras independientes ${ }^{7}$.

Nuestro estudio forma parte de un esfuerzo académico creciente dirigido a revisar críticamente las experiencias disponibles respecto de la implementación del Estado regulador en Latinoamérica, aunque con un enfoque diferente. En contraste con otro tipo de trabajos, nuestra investigación no distingue el sector de la economía al que pertenece la agencia reguladora, y aportamos evidencia empírica relacionada con una regla institucional específica: el sistema de nombramiento de las autoridades superiores de dichas agencias. Buscamos entender el impacto del modelo institucional de nombramiento en el perfil de quienes son nombrados. Como en el contexto Latinoamericano el presidencialismo es un factor elemental para entender los nombramientos de este tipo de agencias, un actor relevante e ineludible en nuestro estudio es el Presidente.

Obtuvimos nuestros datos de un estudio focalizado en Chile. A diferencia de otros trabajos, esta investigación se enfoca en un mecanismo particular de independencia formal, dentro un solo país y a lo largo de un periodo de tiempo relativamente largo. Al igual que otros países latinoamericanos, Chile posee un presidencialismo fuerte y, sin perjuicio de que el Presidente realice la mayoría de los nombramientos sin mayores controles, la evolución institucional chilena ha desarrollado modelos de nombramiento especiales que restringen la influencia del Presidente en los nombramientos, tal como ocurre con el rol del Senado en la confirmación de varios de las designaciones examinadas. Otros modelos de nombramientos de agencias reguladoras en Latinoamérica también siguen modelos que le asignan un rol al parlamento, el que puede ayudar a explicar el nivel de independencia de las agencias ${ }^{8}$.

5 Ver, por ejemplo, la interesante combinación de metodologías para medir la independencia formal de las agencias reguladoras, en Montoya MA, Trillas, F. The Measurement of the Independence of Telecommunications Regulatory Agencies in Latin America and the Caribbean. Utilities Policy. 15, 2007: 182-190.

6 Varios se limitan a estudiar sectores particulares de la economía, típicamente telecomunicaciones y obras públicas. Ver GutiérRez, LH, supra nota 4; Montoya MA, Trillas, F., supra nota 5, 182-190; Martínez-Gallardo C, Murillo MV, supra nota 3; Trillas F, Montoya MA. Commitment and Regulatory Independence in Practice in Latin American and Caribbean Countries. Competition and Regulation in Network Industries. 12, 2011: 27-56.

7 Pavón Mediano, A. Agencies' formal independence and credible commitment in the Latin American regulatory state: A comparative analysis of 8 countries and 13 sectors. Regulation \& Governance, 2018.

8 Ver, por ejemplo, la explicación metodológica contenida en el apéndice del estudio de MonTOYA MA, TRILlas, supra nota 5, 182-190 
Así, por ejemplo, un estudio que comprendió 36 agencias del sector financiero y de telecomunicaciones, demostró que en nueve de ellas existe algún nivel de contrapeso respecto del gobierno incumbente, y en seis de dichos casos los nombramientos requieren ratificación de la legislatura (uno en Bolivia, Panamá, Perú y Paraguay, y dos en Ecuador $)^{9}$.

Nuestro estudio examina cerca de 200 procesos de nombramientos realizados entre 1990 y 2016, de funcionarios directivos, pertenecientes a veinte organismos chilenos que tienen incidencia en la regulación económica de dicho país. Dichos organismos son equivalentes a las Agencias Reguladoras Independientes. El periodo señalado incluye la consolidación del proceso de privatizaciones y reforma del Estado iniciado durante la década de los ochenta, así como las modificaciones a este enfoque que comienzan a desarrollarse con la incorporación de Chile a la Organización para la Cooperación y Desarrollo Económico (OCDE) el 2010.

El objetivo central de este artículo es comparar los nombramientos donde el Senado debe confirmar a los candidatos presentados por el Poder Ejecutivo, con aquellos donde este último lidera los nombramientos sin el contrapeso institucional de este otro poder del Estado. En síntesis, nuestra evidencia muestra que los nombramientos de autoridades reguladoras en que participe directamente el Senado tienen mejores antecedentes profesionales. A su vez, el tiempo de permanencia de los directivos es dos veces más largo y resulta mucho más probable que se mantengan en sus cargos después de un cambio de gobierno. Algo similar ocurre con los nombramientos en que el Senado tiene una influencia indirecta o delegada, donde además los directivos vienen con mayor frecuencia desde fuera del sector público y tienen una trayectoria académica significativamente más rica.

Teniendo en cuenta que la participación del Senado persigue fomentar la estabilidad y calidad técnica de las autoridades reguladoras, la evidencia sugiere que estos mecanismos de autonomía institucional han sido exitosos. En efecto, existe un grado significativo de correlación entre la exigencia de confirmación ante el Senado como mecanismo formal y el comportamiento de las autoridades reguladoras en la práctica, al menos a la luz de los principales indicadores utilizados en Derecho Comparado. Aunque el volumen de evidencia impide documentar una cadena causal, nuestro trabajo permite mostrar que la exigencia de confirmación ante el Senado forma parte de un diseño institucional que señaliza un mayor compromiso con la autonomía reguladora.

El análisis ofrecido aquí proporciona evidencia relevante para el debate sobre cuáles son los mejores mecanismos institucionales para fomentar la autonomía de las agencias reguladoras. Este debate está ciertamente vivo

9 Jordana, J., y Ramió, C. Delegation, Presidential Regimes, and Latin American Regulatory Agencies. Journal of Politics in Latin America, Vol. 2, n. ${ }^{\circ}$ 1, 2010: 15-18. 
en Chile, donde distintos académicos han propuesto incrementar el número de autoridades sujetas a confirmación por parte del Senado o consagrar este mecanismo a nivel constitucional ${ }^{10}$. La mayor parte de esta literatura se enfoca en aspectos cualitativos y análisis de casos ${ }^{11}$, siendo la principal excepción el estudio de Enteiche, quien analiza nueve reguladores económicos y reporta que gran parte de los directivos designados sin acuerdo del Senado dejaron sus cargos luego del cambio de gobierno ocurrido el año 2010, mientras que algo similar ocurrió después del cambio de gobierno de $2014^{[12]}$. Nuestro trabajo complementa y enriquece esta intuición presentando información más detallada respecto de los directivos, un mayor número de agencias y un período de tiempo más largo.

Este análisis también puede ser relevante para la literatura latinoamericana. Muchos países de la región han realizado reformas recientes con el objetivo de limitar la influencia del gobierno en las respectivas autoridades reguladoras ${ }^{13} \mathrm{y}$, al igual que en Chile, otros países también cuentan con sistemas de nombramientos múltiples en contextos de presidencialismo fuerte, incluyendo procedimientos dominados por el Presidente sin mayor control, y modelos que restringen el poder del Presidente en las designaciones ${ }^{14}$.

Nuestro artículo no examina ciertas variables que pueden influir en la autonomía de la institución, como su presupuesto y las remuneraciones de sus directivos, entre otras. Por esta misma razón, si bien nuestros datos proporcionan evidencia útil para el debate sobre la autonomía de las agencias reguladoras, ellos no son suficientes para establecer una aproximación holística relativa a la independencia de dichas instituciones.

10 García G., J., y Sergio Verdugo R., S., supra nota 10; Sierra, L. (ed.) Diálogos Constitucionales. Santiago: Centro de Estudios Públicos, 2015; Zárate, S., supra nota 10; Soto, S., supra nota 10; Enteiche Rosales, N. Superintendencias: Una Necesaria Autonomía Constitucional. En Alvear, J. y Covarrubias, I. (eds.). Desafios Constitucionales. Propiedad, Debido Proceso, Libertad Religiosa, Régimen Político y Administrativo. Valencia: Tirant lo Blanch, 2017. Ciertamente, otros autores discuten la autonomía de las agencias reguladoras desde una perspectiva crítica CAMACHO CEPEDA, G. La problemática de la potestad normativa de las superintendencias. Actas XXXIV Jornadas de Derecho Público de 2004, 2005: 423-32; GARCía G., J. ¿Inflación de superintendencias? Un diagnóstico crítico desde el derecho regulatorio. Actualidad Jurídica, Vol. 19, 2009: 327-72; DíAZ DE VALDÉs J.J. Anomalías Constitucionales de Las Superintendencias: Un Diagnóstico. Estudios Constitucionales, Vol. 8, n. ${ }^{\circ}$ 1, 2010: 249-82; LARRAín, Guillermo y LARRAín, M.. Hacia una reforma de la institucionalidad financiera en Chile. Documento de Trabajo, Universidad Del Desarrollo 12, 2010; Cordero Vega, L., y García, J. Elementos para la discusión sobre agencias independientes en Chile. El caso de las superintendencias. Anuario de Derecho Público, 2012: 415-35.

11 Ver, e.g., RAJEVIC, E. El Consejo para la transparencia como administración independiente. En Transparencia en la administración pública. Santiago: Legal Publishing, 2010: 231-47.

12 EnTEiche Rosales, supra nota 10.

13 Guasch, J., y SPILleR, P., supra nota 2; JoRdana, J., y Ramió, C., supra nota 8.

14 GutiérRez, LH, supra nota 4, 231. 
La sección siguiente (2) resume el debate sobre la autonomía de las agencias reguladoras e identifica el rol que históricamente ha cumplido el Senado dentro del sistema político chileno. La sección siguiente (3) propone una matriz para sistematizar los distintos mecanismos de nombramiento de autoridades reguladoras en Chile y discute los efectos esperados de cada mecanismo. En seguida (4), comparamos el desempeño relativo de los cuatro modelos principales de nombramiento, adaptando los métodos más utilizados en Derecho Comparado. La ultima (5) sección sintetiza las conclusiones.

\section{EL ROL DEL SENADO EN CHILE Y EL DEBATE SOBRE LA AUTONOMÍA DE LAS AGENCIAS}

Al igual que el resto de Latinoamérica, el sistema constitucional chileno sigue un modelo presidencial, dentro del cual el Senado constituye uno de los principales mecanismos de freno y contrapeso del Presidente ${ }^{15}$. Las leyes no pueden promulgarse sin aprobación del Senado, quien además actúa como jurado frente a posibles acusaciones constitucionales, resuelve contiendas de competencias entre los otros dos poderes del Estado, y participa en el nombramiento de un número importante de autoridades, entre otras atribuciones ${ }^{16}$. En el ámbito de la regulación económica, el Senado influye mediante la aprobación o rechazo del nombramiento de directivos de agencias reguladoras. Entre ellas, se encuentra la confirmación del Contralor General de la República, los Consejeros del Banco Central y de la Comisión de Mercados Financieros. Enseguida, el Senado también tiene una influencia indirecta o delegada en el

15 Ver Aninat, C. Balance de Poderes Legislativos en Chile. ¿Presidencialismo Exagerado o Base de un Sistema Político Cooperativo? Política, Vol. 47, 2006: 127-148. Aunque esto sigue siendo cierto actualmente, es importante destacar que el Senado perdió algunas atribuciones con una reforma constitucional del año 2005 destinada a reducir los enclaves autoritarios de la Constitución de 1980. Ensalaco, M. In with the New, Out with the Old? The Democratising Impact of Constitutional Reform in Chile. Journal of Latin American Studies, Vol. 26, n. 2 , 1994: 409-29, 419; CAREY, J. "Parties, Coalitions, and the Chilean Congress in the 1990's. En Morgenstern, S. y NaCIF, B. (eds.). Legislative Politics in Latin America. Cambridge University Press, 2002: 222-53, 223; LondRegan, J. Appointment, Reelection, and Autonomy in the Senate of Chile. En Morgenstern, S. y NACIF, B. (eds.). Legislative Politics in Latin America. Cambridge University Press, 2002, 341-76; Montes, E., y Vial, T. The Constitution-Building Process in Chile: The Authoritarian Roots of a Stable Democracy. Stockholm: International IDEA, 2005, 19.

16 Las atribuciones del Senado están enumeradas en el artículo 53 de la Constitución chilena. En términos generales, en todas estas atribuciones existe una distinción entre el impulso inicial y la participación posterior. Los sistemas parlamentarios entregan al Poder Legislativo el impulso inicial tanto en materia legislativa, como tratándose del nombramiento de autoridades reguladoras y la remoción de autoridades políticas. En contraste, la intensidad de un sistema presidencial suele medirse identificando cuantas facultades de impulso inicial son entregadas al Poder Ejecutivo. McCARTY, N. The Appointments Dilemma. American Journal of Political Science, Vol. 48, n..$^{\circ}$, 2004: 413-428. Chile tiene un modelo presidencial fuerte, porque el impulso inicial siempre corresponde al Poder Ejecutivo. Ver, por ejemplo, NAVIA, P. Living in Actually Existing Democracies: Democracy to the Extent Possible in Chile. Latin American Research Review, Vol. 45, special issue, 2010: 298-328. 
nombramiento de los miembros de los directivos de otras instituciones, tales como el Tribunal de Defensa de la Libre Competencia; y en menor medida, del Panel de Expertos, un órgano relevante para la aplicación de la legislación eléctrica. Ello contrasta con lo que sucede respecto del nombramiento de la gran mayoría de las autoridades reguladoras en Chile, incluyendo una decena de superintendencias que regulan y fiscalizan el cumplimiento de normas en sectores específicos como la electricidad, el mercado de valores o el medio ambiente ${ }^{17}$; así como otras fiscalías, subsecretarías y servicios que supervisan la regulación en materia de impuestos, aduanas, protección al consumidor o libre competencia. En todas estas instituciones el Presidente de la República tiene amplias atribuciones para nombrar a los funcionarios directivos, ya sea discrecionalmente o con el apoyo del denominado sistema de Alta Dirección Pública (“ADP”).

En Chile, el mecanismo de confirmación ante el Senado fue incorporado dentro de un conjunto de reformas de la década de los ochenta, expresamente dirigidas a fortalecer el Banco Central y la Contraloría General de la República $^{18}$. La idea central era seguir el ejemplo de Estados Unidos respecto de las denominadas agencias reguladoras independientes ${ }^{19}$. Con todo, ciertas atribuciones limitadas para revisar nombramientos existían también en la Constitución de 1925. Este antecedente es interesante porque los constituyentes de 1925 percibían al Senado como un órgano que debía estar alejado de la política partidista ${ }^{20}$. Aunque esta idealización contrasta con la práctica institucional, algunos de los principales constitucionalistas chilenos parecieran mantener esta postura, sosteniendo que la intervención del Senado busca asegurar la idoneidad y el prestigio del postulante ${ }^{21}$.

17 Las superintendencias chilenas están dentro del Poder Ejecutivo, pero forman parte de lo que se conoce administración descentralizada. Su dirección está entregada a una sola persona, sin que exista una vinculación jerárquica formal con el Presidente de la República o el ministerio respectivo. Las superintendencias cuentan además con un patrimonio propio que les permite administrar su presupuesto con autonomía, aunque la determinación anual está sujeta a las mismas negociaciones con el Ministerio de Hacienda que los restantes organismos de gobierno. Finalmente, tienen una personalidad jurídica separada que las habilita para impartir normas de general aplicación, sancionar a particulares y representar judicialmente los intereses de la agencia.

18 Cordero Vega, L., y García, J., supra nota 10.

19 Los antecedentes de las reformas legales adoptadas entre 1973 y 1990 son escasos, debido a que, durante el régimen militar de Augusto Pinochet, Chile carecía de un Congreso y los estándares de transparencia en materia legislativa eran bajos. Con todo, el mecanismo de confirmación ante el Senado fue extendido durante 1997 al nombramiento de los jueces de la Corte Suprema, reconstruyéndose en esa oportunidad los antecedentes legislativos de las reformas anteriores.

20 Bronfman, A., Cordero, E., y Aldunate, E. Derecho Parlamentario Chileno.Funciones y Atribuciones del Congreso Nacional. Santiago: Legal Publishing - Thomson Reuters, 2013.

21 Pfeffer, E. Manual de Derecho Constitucional, Vol. 2. Ediar Conosur, 1990; Silva, A. Tratado de Derecho Constitucional, Vol. VI. Santiago: Editorial Jurídica de Chile, 2000; CEA Egaña, J. Derecho Constitucional Chileno, Vol. III. Santiago: Ediciones uc, 2013. 
Desde la perspectiva de la separación de poderes, el poder del Senado de confirmar los nombramientos hechos por el Ejecutivo, supone limitar la discrecionalidad del Presidente y fomentar la independencia de las autoridades reguladoras ${ }^{22}$. Siguiendo esta misma línea, varios autores chilenos consideran que la exigencia de autorización ante el Senado es una manera de fomentar la independencia de las agencias reguladoras ${ }^{23}$. Con todo, también hay una parte importante de la literatura que disputa la capacidad de este tipo de mecanismos formales para fortalecer la independencia de las autoridades reguladoras ${ }^{24}$. Muchas veces el Senado chileno es objeto de críticas porque sus procesos de confirmación son poco transparentes y siguen criterios excesivamente partidistas. Estas críticas, sin embargo, suelen ser ajenas a los nombramientos de autoridades reguladoras y apuntan a la politización de los nombramientos en el Tribunal Constitucional ${ }^{25}$, la Corte Suprema ${ }^{26}$ o el Consejo para la Transparencia ${ }^{27}$.

De este modo, un primer desafío en el debate sobre autonomía institucional consiste en sistematizar la relación existente entre mecanismos formales como la confirmación ante el Senado, y el comportamiento efectivo de las agencias. En otras palabras, ¿en qué debiera traducirse un cambio en los niveles de independencia formal? Para responder esta pregunta, revisemos

22 LEwIs, D. Presidents and the politics of agency design: Political insulation in the United States government bureaucracy. California: Stanford University Press, 2004.

23 García G., J., y Sergio Verdugo R., S., supra nota 10; LarRaín, Guillermo y LarRaín, M. supra nota 10; Cordero VeGA, L., y García, J., supra nota 10; EnTEIChe Rosales, supra nota 10 .

24 A ello se agregan, además, objeciones de fondo respecto del valor de la autonomía. Las autoridades reguladoras típicamente carecen de la legitimidad democrática que tienen las autoridades elegidas por los votantes. Por esta razón, la exigencia de confirmación ante el Senado suele ser vista como una manera de limitar el principio mayoritario. Ver, por ejemplo, CUTLER, L., and Johnson, D. Regulation and the Political Process. Yale Law Journal 84, 1974: 1395; MAJONE, G. Nonmajoritarian institutions and the limits of democratic governance: a political transaction-cost approach. Journal of Institutional and Theoretical Economics, Vol. CLVII, 2001: 57-78. En Chile, curiosamente, parte de la literatura asocia la exigencia de confirmación ante el Senado con el principio de frenos y contrapesos. Bronfman, A., Cordero, E., y Aldunate, E., supra nota 20. Otra parte de la literatura lo concibe como una manera de legitimar parcialmente el nombramiento de estas autoridades. RAJEVIC, E., supra nota 11; LARRAÍn, Guillermo y Larraín, M. supra nota 10; García G., J. Ni Césares, Ni Caudillos, Ni Redentores: El Fin Del Hiperpresidencialismo Chileno. En García García, J. (ed.). ¿Nueva Constitución o Reforma? Nuestra Propuesta: Evolución Constitucional. Santiago: Thomson Reuters, 2014, 351-76.

25 Ríos, L. La Generación Del Tribunal Constitucional. En Nogueira Alcalá, H. (ed.) Jurisdicción Constitucional en Chile y América Latina: Presente y Prospectiva. Santiago: Universidad de Talca - Lexis Nexis, 2005, pp. 451-66; Bassa MERCADO, J. El Tribunal Constitucional en la Constitución Chilena Vigente. En Bassa Mercado, J., Ferrada Bórquez, J. y Viera Álvarez, C. (eds.). La Constitución Chilena. Una Revisión Crítica a Su Práctica Política. Santiago: Lom, 2015, pp. 253-84.

26 Sото, S. Relaciones entre el Congreso Nacional y el Poder Judicial: La Importancia de la Apertura. Ius et Praxis, Vol. 13, n. ${ }^{\circ}$ 1, 2007: 135-166.

27 RAJEVIC, E., supra nota 11. 
brevemente cuales son los objetivos detrás de un diseño institucional que limita la capacidad de influencia del gobierno.

En términos generales, una de sus principales ventajas consiste en otorgar estabilidad a las reglas que gobiernan una determinada actividad económica. Autores como Levy y Spiller señalan que la autonomía institucional persigue que las distintas coaliciones políticas converjan hacia una posición de consenso, la cual se mantiene estable en el tiempo y reduce los costos de estar cambiando las reglas cada vez que se produce un cambio electoral ${ }^{28}$. En particular, el mecanismo de confirmación ante el Senado generaría que el candidato de la coalición política gobernante tenga que convencer a miembros de la coalición opositora ${ }^{29}$. Ello favorecería que los candidatos presentados a confirmación tengan una posición política más moderada que la que tendría un candidato designado unilateralmente por la coalición gobernante. Además, impediría que los nombramientos y remociones sean utilizados como un mecanismo para disciplinar el comportamiento del regulador ${ }^{30}$. Si ello es así, entonces los argumentos de quienes critican el poder del Senado chileno para confirmar o rechazar el nombramiento de ciertas autoridades, parecieran poco persuasivos. Contrario a dichas opiniones, una primera expectativa que podríamos formular es que aquellas autoridades cuyo nombramiento es sujeto a confirmación por parte del Senado tiendan a mantenerse más tiempo en sus cargos y evidencien una mayor neutralidad política.

En segundo lugar, los mecanismos de independencia formal también buscan fomentar la calidad técnica de las decisiones administrativas ${ }^{31}$. La necesidad de convencer al Senado respecto de las virtudes del candidato exige buscar personas cuya capacidad técnica se vea reflejada en antecedentes objetivos y fáciles de acreditar, tales como la formación académica o la experiencia profesional. Al menos, el Presidente de la República tiene incentivos para nominar a un candidato que tenga antecedentes lo suficientemente elevados como para que sus opositores en el Senado no argumenten que el candidato

28 LeVy, B., y SpILler, P. Regulations, Institutions and Commitment. New York: Cambridge University Press, 1996.

29 El mismo argumento puede realizarse dentro de una coalición lo suficientemente fuerte para controlar el Senado, considerando ahora las distintas facciones y tendencias que lo componen. El punto central es que la exigencia de confirmación hace que resulte más difícil nombrar y remover una autoridad reguladora KydLAND, F. y PRESCOTT, E. Rules rather than discretion: The inconsistency of optimal plans. The Journal of Political Economy, 1977: 473-491. Como señala Lewis, ello genera que el gobierno tenga menor capacidad de influencia sobre esa autoridad reguladora que la que tiene respecto de un ministro o jefe de servicio público situados dentro de la cadena jerárquica tradicional del Poder Ejecutivo. Ver LewIs, D., supra nota 22.

30 Kiewiet, DR., y McCubbins, MD. The logic of delegation. Chicago, University of Chicago Press, 1991.

31 Aghion, Philippe y Tirole, J. Formal and real authority in organizations. Journal of Political Economy, Vol. 105(1), 1997: 1-29; Bendor, J. y MeIrowitz, A. Spatial models of delegation. American Political Science Review, Vol. 98(2), 2004: 293-310; StePHENSON, M. Optimal Political Control of the Bureaucracy. Michigan Law Review, 2008: 53-110. 
elegido es débil desde una perspectiva técnica. Así, utilizando el enfoque tradicional de Wilson, la exigencia de confirmación sería un mecanismo para profesionalizar la burocracia ${ }^{32}$. En otras palabras, en este tipo de nombramientos la idoneidad técnica del candidato se vuelve un elemento decisorio importante, el que incluso puede ser superior al criterio de lealtad política del candidato, o de su trayectoria dentro del gobierno que promueve su nombramiento $^{33}$. De este modo, una segunda expectativa es que las autoridades cuyo nombramiento se encuentra sujeto a confirmación por parte del Senado muestren también mejores antecedentes profesionales y mayor experiencia directiva fuera del sector público. Esta expectativa es consistente con la intuición de la otra parte de la literatura chilena, citada previamente, quienes ven al Senado como un mecanismo para mejorar el carácter técnico de los nombramientos.

Ambas expectativas, la neutralidad política y la idoneidad técnica de los directivos nombrados, parecen razonables a la luz de la experiencia en Derecho Comparado. En el contexto europeo, existe consenso en cuanto a que mayores niveles de independencia institucional están asociados a una mayor estabilidad en la dirección de las autoridades reguladoras ${ }^{34}$, así como también a mejores antecedentes profesionales por parte de los funcionaros directivos $^{35}$ y menores niveles de afiliación política ${ }^{36}$. Por su parte, y específicamente respecto del mecanismo de confirmación ante el Senado, la

32 WiLson, J. Bureaucracy: What government agencies do and why they do it. New, 1989.

York, Basic Books.

33 En términos generales, idoneidad técnica y lealtad política suelen ser concebidos como valores antagónicos. Aunque ello sea necesariamente así en todos los casos, suele asumirse que a medida que aumenta la lealtad política de un candidato, disminuiría su idoneidad técnica, y viceversa. Ello asume que las decisiones de una autoridad reguladora están gobernadas por dos grupos de razones: las prioridades del gobierno y los antecedentes del caso concreto. Mientras la lealtad política entrega mayor peso relativo a las prioridades del gobierno, la capacidad técnica privilegia un análisis crítico de los antecedentes concretos del caso. En el modelo canónico de Bawn, el comportamiento de las autoridades políticamente leales resultaría mucho más predecible que el de las autoridades técnicamente competentes, pero también menos ajustado a las necesidades del caso concreto. BAWN, K. Political control versus expertise: Congressional choices about administrative procedures. American Political Science Review, Vol. LXXXIX, n. ${ }^{\circ} 1,1995$ : $62-73$.

34 Ennser-Jedenastik, L. The Politicization of Regulatory Agencies: Between Partisan Influence and Formal Independence. Journal of Public Administration Research and Theory, 2016: 507-518.

35 Bach, T., y Veit, S. The Determinants of Promotion to High Public Office in Germany: Partisan Loyalty, Political Craft, or Managerial Competencies? Journal of Public Administration Research and Theory. 28, no. 2, 2017: 254-269.

36 BACh, T., HAMmerschmid, G., y LÖFfLe, L. More delegation, more political control? Politicization of senior-level appointments in 18 European countries. Public Policy and Administration: 0952076718776356, 2015; BAUER, MW y EGE, J. Politicization within the European Commission's bureaucracy. International Review of Administrative Sciences, Vol. 78, n. ${ }^{\circ} 3$, 2012: 403-424. 
evidencia en Estados Unidos también muestra que este tipo de funcionarios gozan de mayor estabilidad en sus cargos, a la vez que tienen mejores antecedentes profesionales y menores niveles de afiliación política ${ }^{37}$. Con todo, si miramos de cerca esta tendencia general, también existen excepciones. En varios países europeos, la incorporación de mecanismos de independencia formal se ha visto acompañada por una primera generación de nombramientos que privilegiaría la lealtad política de los candidatos, y donde la racionalidad sería atenuar temporalmente el impacto de estos cambios institucionales ${ }^{38}$. A su vez, en Estados Unidos existen varios gobiernos que aprovecharon mayorías transitorias para nombrar aliados políticos y hacer más difíciles cambios regulatorios futuros, en lo que se conoce como una dinámica de "atrincheramiento" ${ }^{39}$. Finalmente, la tendencia hacia la profesionalización también puede verse frenada cuando un gobierno se prolonga el tiempo, toda vez que elegir personas con menos experiencia y peores capacidades técnicas permitiría reducir el riego de interferencia con la agenda política de un presidente que se va haciendo cada vez más fuerte ${ }^{40}$. Desde esta perspectiva, parece razonable continuar explorando la conexión entre la independencia formal y material de las agencias reguladoras.

\section{CUATRO MODELOS DE NOMBRAMIENTO}

Para efectos de sistematizar la experiencia chilena en materia de nombramientos, seguimos el enfoque de Pardow y dividimos el proceso de designación en tres etapas: selección de una lista corta, designación del candidato y confirmación por parte del Senado ${ }^{41}$. El proceso generalmente comienza con la recepción y análisis de los antecedentes de todos los posibles candidatos, los que en ciertas oportunidades son recibidos en un concurso público, mientras que en otras se realiza en el marco de una búsqueda privada. Esta etapa concluye con la elaboración de una lista corta, típicamente con tres o cinco candidatos. Posteriormente, las personas incluidas en esta lista corta son invitadas a una audiencia, entrevista u otra forma de interacción presencial con los responsables del nombramiento. Esta otra etapa concluye con la elección del funcionario directivo. Finalmente, tratándose de ciertas

37 Lewis, D. The politics of presidential appointments: Political control and bureaucratic performance. Nueva York: Princeton University Press, 2010.

38 ENNSER-JEDENASTIK, L., supra nota 34.

39 Wood, D. y Bothe, J. Political transaction costs and the politics of administrative design. Journal of Politics, Vol. LXVI, n. ${ }^{\circ} 1,2004$ : 176-202.

40 Krause, GA., y O'Connell, A. Experiential learning and presidential management of the us federal bureaucracy: Logic and evidence from agency leadership appointments. American Journal of Political Science, Vol. 60, n. ${ }^{\circ}$ 4, 2016: 914-931.

41 Pardow, D. ¿Técnicos o políticos?: Radiografía del Sistema de Nombramiento de Directivos en Agencias Reguladoras Independientes, 2018 (inédito en consulta con autor). 
autoridades reguladoras, su designación debe ser confirmada por el Senado, quien decide sobre ella en una sesión citada especialmente al efecto, antes de audiencia con el directivo designado y sujeta a un quórum que varía desde la simple mayoría a los dos tercios.

Bajo este marco conceptual, identificamos cuatro modelos diferentes, que explicamos a continuación:

\subsection{El Modelo Discrecional}

En este modelo de nombramiento, el gobierno controla el proceso sin mayores contrapesos. En otras palabras, la última etapa de confirmación ante el Senado está ausente, mientras que las otras dos etapas dependen exclusivamente del Poder Ejecutivo. Este modelo, que podríamos denominar como discrecional, y que otros autores denominan modelo de confianza $a^{42}$, era el más extendido en Chile durante los veinte años que transcurren entre el retorno a la democracia en 1990 y el inicio del proceso de admisión a la OCDE a comienzos de los años $2000^{[43]}$. Como señala García, este mecanismo se aplicaba principalmente a una decena de superintendencias creadas de manera paralela a los procesos de privatización (v.g. administración de pensiones, electricidad y combustibles, servicios sanitarios $)^{44}$, así como a un conjunto de fiscalías, subsecretarías y servicios que actúan igualmente en el ámbito de la regulación económica. Aunque dichas superintendencias tienen una autonomía formal, el vínculo con el Ejecutivo es fuerte. Desde una perspectiva institucional, las superintendencias son servicios públicos descentralizados que cuentan con su propia ley orgánica, donde se establecen ciertos mecanismos de independencia formal respecto del Poder Ejecutivo. Este mismo diseño institucional se sigue en los casos del Servicio Nacional del Consumidor, el Servicio Nacional de Aduanas, el Servicio de Impuestos Internos, la Comisión Nacional de Energía o la Fiscalía Nacional Económica. Ahora bien, mientras las superintendencias usualmente tienen una competencia material que está restringida al mercado que pasaba a liberalizarse, estos

42 Cordero Vega, L., y García, J., supra nota 10.

43 García G., J., y Sergio Verdugo R., S., supra nota 10. La estructura institucional de la regulación económica en Chile puede dividirse en tres períodos, todos marcados por la visión internacionalista y tecnocrática de las reformas a que dieron lugar. El primero se relaciona con la misión Kemmerer de principios del siglo xx, la estabilidad de la política monetaria y la creación de instituciones como la Contraloría General de la República o el Banco Central. El segundo comienza con el programa de privatizaciones impulsado durante el Régimen de Pinochet y se consolida durante los primeros gobiernos democráticos de la década de los noventa. El tercer periodo está marcado por el proceso de admisión ante la OCDE y las recomendaciones sobre reformas institucionales por parte de este organismo. Ver, PARDOw, D. ¿Control o autonomía?: el debate sobre agencias reguladoras Independientes, 2017 (inédito en consulta con autor).

44 GARCía G., J., supra nota 10. 
otros organismos cuentan con una competencia definida de manera funcional y que se extiende a mercados diversos ${ }^{45}$.

Este modelo discrecional se caracteriza por dos elementos: la ausencia de contrapesos al Poder Ejecutivo y la opacidad en la toma de decisiones ${ }^{46}$. La ausencia de contrapesos se manifiesta en que el nombramiento y remoción del funcionario directivo son decididos exclusivamente por el gobierno y sin necesidad de justificar su decisión. Normalmente, solo existe un control formal por parte de la Contraloría General de la República, quien supervisa que la decisión del gobierno haya sido adoptada por la autoridad competente y el candidato cumpla los requisitos legales ${ }^{47}$. Por su parte, la opacidad del proceso se manifiesta en que la selección inicial de los posibles candidatos se realiza mediante búsquedas privadas, típicamente a través de los partidos políticos asociados al gobierno de turno y cuya única medida de publicidad consiste en la información de los medios de prensa. Asimismo, la interacción con los candidatos incluidos en una lista corta se realiza de manera informal, sin que existan actos administrativos o quede algún tipo de registros sobre el proceso. Los únicos antecedentes del nombramiento son los antecedentes profesionales que se acompañan a la Contraloría General de la República para efectos de la supervisión formal.

Los problemas de arbitrariedad y opacidad en el modelo discrecional llevaron a implementar un segundo modelo de designación, conocido como el sistema ADP.

\subsection{El Sistema ADP}

El modelo ADP se implementó a comienzos del nuevo milenio, siguiendo las recomendaciones de la OCDE sobre la materia ${ }^{48}$. Es importante tener en cuenta que el nuevo modelo modificó el mismo universo de autoridades reguladoras mencionado previamente, esto es, las superintendencias, servicios

45 Esto ha generado una superposición de las facultades reguladoras de las autoridades respectivas, dentro de un mismo mercado. Así, por ejemplo, la Corte Suprema de Chile resolvió hace algunos años una disputa entre el Servicio Nacional del Consumidor y la Superintendencia de Bancos acerca de los requisitos necesarios para modificar el contrato asociado a una tarjeta de crédito. Así también, la Contraloría General de la República arbitró recientemente un conflicto entre el Servicio de Impuestos Internos y la Superintendencia de Pensiones respecto de las consecuencias asociadas a la fusión de una sociedad administradora. Para una sistematización de este y otros conflictos similares, ver Pardow, D. El Servicio Nacional del Consumidor de Chile (SERNAC) y los reguladores sectoriales: buscando mecanismos para una mejor coordinación . Economía y Política. 2, n. ${ }^{\circ}$ 2, 2015: 107-136.

46 Cordero Vega, L., y García, J., supra nota 10.

47 CARmona, C. Una aproximación general sobre las superintendencias desde la perspectiva del Derecho, Santiago, 2005 (en consulta con el autor).

48 Costa, R., y W aissbluth, M. Tres años del Sistema de Alta Dirección Pública en Chile: balances y perspectivas. Documento de Trabajo, Serie Gestión, Nº94. Santiago de Chile: Control de Gestión (CEGES), Departamento de Ingeniería Industrial, Universidad de Chile, 2007. 
y otros organismos descentralizados que actúan en el ámbito de la regulación económica $^{49}$. La literatura chilena parece asumir que las modificaciones introducidas por el nuevo modelo fortalecen la transparencia de las designaciones y los contrapesos institucionale ${ }^{50}$, además de garantizar un cierto grado de profesionalización de los candidatos seleccionados ${ }^{51}$. Para garantizar los contrapesos al gobierno, la transparencia del sistema de nombramiento y un nivel mínimo de idoneidad técnica de los postulantes, toda la etapa de selección inicial de candidatos se realiza a través el sistema ADP, cuya estructura institucional está situada fuera del gobierno y bajo mecanismos de independencia formal relativamente altos. La remoción de un directivo nombrado bajo este modelo, por su parte, también está sujeta a restricciones que limitan la discrecionalidad del gobierno ${ }^{52}$.

El proceso comienza con un concurso público de antecedentes y todos los candidatos incluidos en la lista corta son sujetos a entrevista por parte de los responsables del nombramiento, quedando debido registro de todo lo anterior. Con todo, en este modelo la selección del candidato sigue correspondiendo al Poder Ejecutivo, sin que resulte necesario su confirmación ante el Senado. Este sistema ha sido celebrado por una parte importante de los autores chilenos, quienes típicamente promueven que otras agencias reguladoras también sigan este modelo ${ }^{53}$. Con todo, otros autores estiman que, si bien el sistema de ADP eleva los estándares de transparencia, control y profesionalización, entrega pocas garantías de independencia política, como lo probaría el hecho de que los superintendentes sigan teniendo una fuerte dependencia material del gobierno ${ }^{54}$.

\subsection{El Modelo de Confirmación ante el Senado}

La exigencia de confirmación ante el Senado es precisamente lo que distinguiría a nuestro tercer modelo de nombramientos. Esta exigencia fue incorporada

49 Desde su aprobación el año 2004, la aplicación del sistema ADP fue extendiéndose gradualmente. Por ello, durante los últimos 15 años coexistieron ambos modelos de nombramiento respecto de un conjunto similar de organismos públicos. En este lapso de tiempo, el sistema fue objeto de numerosas reformas dirigidas a mejorar la independencia de su consejo directivo, la manera de realizar los procesos de selección o la utilización de figuras transitorias. Ver GoNzález-Bustamante, B., Olivares, A., Abarca, P., y Molina, E. Servicio civil en Chile, análisis de los directivos de primer nivel jerárquico (2003-13). Revista de Administração Pública, Vol. $\mathrm{L}, \mathrm{n} .{ }^{\circ} 50,2016,59-79$.

50 Zárate, S., supra nota 10; Soto, S., supra nota 10.

51 Hube, C. Hacia un presidencialismo moderado: más herramientas legislativas y de control para el Congreso. En GARCía GARCíA, J. (ed.) ¿Nueva Constitución o Reforma? Nuestra Propuesta: Evolución Constitucional. Santiago: Thomson Reuters, 2014, 377-92.

52 González-Bustamante, B., Olivares, A., Abarca, P., y Molina, E., supra nota 49.

53 ZÁrate, S., supra nota 10; Soto, S., supra nota 10.

54 García G., J., supra nota 10, 214; García G., J., y Verdugo R., S., supra nota 10, 291) 
respecto del Banco Central y la Contraloría General de la República, dos instituciones asociadas a la primera reforma del Estado a comienzos del siglo pasado y cuyos mecanismos de independencia formal fueron fortaleciéndose progresivamente ${ }^{55}$. Teniendo en cuenta el alto prestigio y calidad técnica que alcanzaron ambas instituciones, el mecanismo de confirmación ante el Senado fue extendido a los nombramientos de los miembros del Consejo para la Transparencia en el 2009, y en 2017 a la Comisión de Mercados Financieros ${ }^{56}$. Recientemente, además, una reforma constitucional dispuso que los consejeros del Servicio Electoral deben nombrarse con acuerdo del Senado y actualmente se discute una regla similar para el Consejo Asesor Fiscal en materia de política financiera. Bajo la Constitución de 1925, este sistema también existía para los embajadores y diplomáticos, cuestión que fue vuelta a discutir en el contexto de la reforma constitucional de 2005. Ahora bien, mientras en el caso de los consejeros del Banco Central y del Contralor los procesos de confirmación se realizan uno a uno, en el caso del Consejo para la Transparencia y de la Comisión de Mercados Financieros, los nombramientos se realizan por grupos ${ }^{57}$. En el contexto de un sistema político como el chileno, donde han existido dos coaliciones claramente definidas y que reúnen más de dos tercios de la representación parlamentaria, realizar el proceso de confirmación en grupos permite repartir los cupos disponibles entre los partidos políticos correspondientes. Así, este sistema tiene el riesgo de reproducir la politización que se ha observado en el sistema de nombramientos de la Corte Suprema y del Tribunal Constitucional ${ }^{58}$. Este riesgo es particularmente importante si se considera que algunos autores promueven el establecimiento de agencias reguladoras con consejos directivos colegia$\operatorname{dos}^{59}$, como por lo demás ha ocurrido en muchos países del $\mathrm{OCDE}^{60}$. Tal vez un sistema de designación que impida nombrar varias autoridades de forma simultánea puede disminuir este riesgo. Por último, en este modelo el Poder Ejecutivo conserva libertad para controlar las etapas de selección inicial y designación de candidatos.

55 PARDOw, D., supra nota 38.

56 Vergara, A. Autoridades administrativas independientes (agencias): Mito y realidad de un modelo conveniente para Chile. Revista de Derecho Administrativo Económico, Vol. XXV, 2018: 45-58.

57 Los quórums requeridos para la aprobación del Senado varían, sin que exista una razón clara para dicha variabilidad. Por ejemplo, para confirmar el nombramiento de un consejero del Banco Central, basta la mayoría simple del Senado, para confirmar al Contralor General de la República se exige el voto de tres quintos de los senadores en ejercicio, para el Consejo para la Transparencia se requieren dos tercios, para la Comisión de Mercados Financieros cuatro séptimos y para el Servicio Electoral dos tercios.

58 Soto, S., supra nota 21; BASSA Mercado, J., supra nota 20.

59 Larraín, G., y Larraín, M. supra nota 10; Zárate, S., supra nota 10.

60 Cordero Vega, L., y García, J., supra nota 10. 


\subsection{Nombramientos con Participación de Órganos ya Confirmados por el Senado}

Finalmente, el cuarto modelo de nombramientos consiste en que el nombramiento lo realizan autoridades que a su vez fueron elegidas bajo el modelo de confirmación ante el Senado. Este es el caso del Tribunal de Defensa la Libre Competencia, donde el Banco Central realiza la selección inicial respecto de cuatro de los cinco miembros que componen este organismo ${ }^{61}$. En dos de estos procesos de nombramiento el Banco Central realiza también la designación, mientras que en los otros dos selecciona una terna de candidatos para que sea el Presidente de la República quién realice la designación. El quinto miembro también es designado por el Presidente de la República, aunque en este caso la terna de candidatos es diseñada por la Corte Suprema. El Panel de Expertos Eléctrico sigue un sistema similar, toda vez que la designación y selección de sus siete miembros es realizada por el Tribunal de Defensa la Libre Competencia, nuevamente previo concurso público de antecedentes ${ }^{62}$. Todos estos nombramientos dependen de autoridades que previamente fueron objeto de confirmación ante el Senado, por lo que decidimos agruparlas en una misma categoría, y denominarla modelo delegado.

La incorporación de este último modelo podría ser objeto de críticas, debido a que no se trata del nombramiento de autoridades reguladoras que pertenezcan de alguna manera al Poder Ejecutivo. Mientras el Tribunal de Defensa de la Libre Competencia pertenece al Poder Judicial, el Panel de Panel de Expertos Eléctrico tiene la posición de un cuerpo arbitral con características mixtas entre organismo público y privado ${ }^{63}$. Con todo, ambos organismos son autoridades reguladoras, ya que poseen atribuciones normativas con una influencia determinante en materias tradicionales de la regulación económica. Por lo demás, su caracterización como órganos puramente jurisdiccionales es discutible ${ }^{64}$. Según se veremos más adelante, los resultados de los procesos

61 Esta etapa de selección incluye un concurso público de antecedentes y entrevistas con un grupo limitado de candidatos. El procedimiento de selección está a cargo de la Secretaría General del Banco Central y las entrevistas son realizadas por el Consejo de dicho organismo. Aunque las entrevistas son privadas, se trata de un procedimiento formalizado y donde existen registros de cada una de las actuaciones. Las bases de postulación actualmente vigentes, fueron adoptadas mediante el Acuerdo No. 1242-01-060126, de 26 de enero de 2006.

62 Vergara, A. El Contencioso Administrativo en Materia Eléctrica: Naturaleza jurisdiccional de las funciones del Panel de Expertos. Revista de Derecho de la Universidad Finis Terrae. Vol IX, 2005: 207-229.

63 Vergara, A., supra nota 56.

64 Agüero, F. y Montt, S. Chile. The Competition Law System and the Country's Norms. En: Fox, E. y Trebilcock, M. (eds.) The Design of Competition Law Institutions: Global Norms, Local Choices. Oxford University Press, 2013, 149-193; TAPIA, J., y CORDERO, L. La revisión judicial de las decisiones reguladoras: una mirada institucional. Estudios Públicos. 139, 2015: 7-66. 
de nombramiento en este modelo delegado son similares a los del modelo de confirmación ante el Senado.

\section{COMPARANDO EL DESEMPEÑO RELATIVO}

Utilizamos la base de datos descrita en el artículo de Pardow, la que contiene cerca de 200 nombramientos de funcionarios directivos realizados en Chile entre 1990 y $2016^{[65]}$. En un 50\% de los casos, el nombramiento se realizó utilizando el modelo discrecional. Ello es equivalente a considerar que, en cerca de la mitad de los nombramientos, el Poder Ejecutivo controló íntegramente las tres etapas referidas anteriormente. Enfocándonos ahora en la otra mitad de los casos, un $21 \%$ del total corresponde al segundo modelo de nombramientos. Esto es, procesos donde la selección de candidatos y confección de ternas se realizó a través del sistema ADP. Enseguida, otro 17\% del total corresponde al tercer modelo de nombramientos, donde el gobierno realiza sin mayores contrapesos la selección y designación de candidatos, pero sometiéndose luego al proceso de confirmación ante el Senado. Finalmente, un $12 \%$ del total corresponde al cuarto modelo de nombramientos, dividiéndose en partes equivalentes entre los procesos para designar a los miembros del Tribunal de Defensa de la Libre Competencia y los correspondientes al Panel de Expertos Eléctrico.

Existen dos grupos de datos relevantes para construir nuestro ejercicio comparativo. Primero, están los datos relativos al nivel de independencia institucional asociada con el proceso de nombramiento respectivo. Segundo, están también aquellos datos referidos a la biografía de las personas designadas. Respecto del primer grupo de datos, hay que distinguir entre dos aproximaciones diferentes para medir o identificar el nivel de independencia institucional. El enfoque de Gilardi considera los aspectos formales de la independencia, utilizando un índice que compila las respuestas a un conjunto de preguntas estructuradas sobre el diseño institucional del organismo ${ }^{66}$. Este índice varía entre cero y uno, representando de manera creciente las diferentes barreras formales que enfrenta el Poder Ejecutivo a la hora de

65 La base de datos citada reconstruye la historia institucional de cada uno de los organismos señalados en la sección anterior, incluyendo una definición de los periodos institucionalmente relevantes y un listado de todas sus autoridades superiores. Se registran distintas variables relativas al proceso de nombramiento y una biografía estructurada de la persona efectivamente designada. Tanto la base de datos, como el detalle con las fichas de investigación puede consultarse en https:// www.researchgate.net/project/Dieseno-institucional-de-la-agencias-regulatorias-independientesARI-en-Chile

66 GILARDI, F. Policy credibility and delegation to independent regulatory agencies: a comparative empirical analysis. Journal of European Public Policy, Vol. IX, n. ${ }^{\circ} 9$ (6), 2002: 873-893. 
ejercer influencia sobre el organismo respectivo ${ }^{67}$. En contraste, existen otros enfoques que apuntan a materializaciones concretas de la independencia institucional, como la duración en el cargo de los funcionarios directivos o la probabilidad de mantenerse en dicho cargo después de producido un cambio de gobierno. Respecto del segundo grupo de datos (v.g. las biografías), se incluyen aspectos biográficos como el nivel de calificación profesional de los funcionarios directivos, la intensidad de su afiliación política y el trabajo en que se desempeñaban antes de su nombramiento.

TABLA 1. COMPARACIÓN ENTRE DISTINTOS MODELOS DE NOMBRAMIENTO

\begin{tabular}{|l|c|c|c|c|c|}
\hline \multicolumn{1}{|c|}{ Parámetro de comparación } & $\begin{array}{c}\text { Modelo } \\
\text { discrecional }\end{array}$ & $\begin{array}{c}\text { Modelo } \\
\text { ADP }\end{array}$ & $\begin{array}{c}\text { Modelo } \\
\text { Senado }\end{array}$ & $\begin{array}{c}\text { Modelo } \\
\text { delegado }\end{array}$ & $\begin{array}{c}\text { Resultados } \\
\text { ANOvA }\end{array}$ \\
\hline Índice de independencia formal & $49.81 \%$ & $49.90 \%$ & $87.94 \%$ & $77.93 \%$ & $0 * * *$ \\
\hline Días de duración en el cargo & 1,189 & 1,084 & 2,653 & $2,027.67$ & $0 * * *$ \\
\hline Índice de afiliación política & $31.59 \%$ & $17.05 \%$ & $34.18 \%$ & $18.83 \%$ & 0.67 \\
\hline Índice de calidad profesional & $45.46 \%$ & $45.99 \%$ & $71.51 \%$ & $58.27 \%$ & $0 * * *$ \\
\hline Nivel de dedicación sector público & $51.48 \%$ & $47.69 \%$ & $42.54 \%$ & $29.57 \%$ & $0.01 *$ \\
\hline Nivel de dedicación sector privado & $33.42 \%$ & $44.60 \%$ & $33.62 \%$ & $28.83 \%$ & 0.45 \\
\hline Nivel dedicación a la academia & $15.10 \%$ & $7.71 \%$ & $23.83 \%$ & $41.60 \%$ & $0.05 *$ \\
\hline Circulación con industria regulada & $29.70 \%$ & $25.81 \%$ & $24.19 \%$ & $29.55 \%$ & 0.49 \\
\hline
\end{tabular}

Fuente: elaboración propia sobre la base de información pública sistematizada para este trabajo

La tabla 1 sistematiza esta información, agrupada conforme a los cuatro modelos de nombramiento descritos anteriormente. Las cuatro columnas centrales muestran el promedio condicional para los valores correspondientes a cada uno de los modelos de nombramiento, mientras que la última columna muestra los resultados de un análisis sencillo de varianza, también conocido como $\mathrm{ANOVA}^{68}$. Este test tiene como objetivo identificar aquellas diferencias

67 Así por ejemplo, la metodología de Gilardi, citado en la nota al pie de página precedente, contempla la pregunta "¿quién designa a las autoridades superiores?" y admite cinco posibles respuestas: (i) uno o dos ministros, respuesta que recibe un puntaje igual a 0; (ii) el Poder Ejecutivo colectivamente, la que recibe un puntaje igual a 0,25; (iii) el Poder Legislativo, la que recibe un puntaje igual a 0,5 ; (iv) un proceso donde participan ambos poderes, la que recibe un puntaje igual a 0,$75 ; \mathrm{y},(\mathrm{v})$ autogeneración por la propia agencia, la que recibe un puntaje igual a 1. También existen preguntas sobre la cantidad de personas que componen la dirección del organismo, duración de su mandato, transparencia del proceso, mecanismos de remoción y otros aspectos del diseño institucional. El índice, a su vez, corresponde a la media aritmética de las respuestas a cada pregunta.

68 En términos generales, el análisis de varianza permite determinar si existen diferencias significativas entre los promedios condicionales de distintos grupos que sometemos a comparación, como sería en este caso los valores promedio de cada modelo de nombramiento. Su principal ventaja es que permite superar las limitaciones de un contraste bilateral, pero manteniendo la estructura de los test paramétricos. Conforme a la convención tradicional en este tipo de test, se consideran estadísticamente significativas aquellas variaciones donde la probabilidad de encontrar 
en los resultados de cada modelo que resultarían estadísticamente significativas. Cada una de las filas de la tabla, por su parte, incorpora los diferentes criterios de comparación que pueden construirse a partir de la información disponible sobre el diseño institucional de los organismos y la biografía de los funcionarios directivos.

Un primer aspecto interesante son las diferencias en términos de independencia formal. La primera fila de la Tabla 1 muestra el índice Gilardi que tendrían, en promedio, aquellos organismos que utilizan ese modelo de nombramiento en particular. Dentro de este contexto, los índices Gilardi correspondientes al modelo de confirmación ante el Senado y al modelo delegado son significativamente más altos que los correspondientes al modelo discrecional y al modelo ADP. Estos datos confirman que los frenos y contrapesos que se contemplan en los dos primeros modelos de nombramiento constituyen una barrera formal a la influencia del Poder Ejecutivo, comparada con los otros dos modelos ${ }^{69}$. Es importante tener presente que la magnitud de la diferencia entre los distintos modelos también está influida por otras características del diseño institucional: los organismos que utilizan los dos primeros modelos de nombramiento, como sucede con el Consejo para la Transparencia, el Tribunal de Defensa de la Libre Competencia, el Panel de Expertos, el Banco Central o la Comisión de Mercados Financieros, tienen estructuras de gobierno colegiado y existen mecanismos de remoción que ponen barreras a la discrecionalidad del Poder Ejecutivo. En contraste, los organismos que utilizan los otros modelos de nombramiento (i.e., modelo discrecional y de ADP), típicamente están dirigidos por una autoridad unipersonal, cuya remoción resulta relativamente sencilla.

En cuanto a los niveles de independencia material, también resulta llamativo que los funcionarios directivos nombrados de acuerdo a los dos primeros modelos (v.g., confirmación por el Senado y modelo delegado) duren significativamente más tiempo en sus cargos. En términos generales, su mandato tiene una extensión promedio superior a los 7 años. Al contrario, los funcionarios elegidos mediante los modelos, discrecional y ADP, duran cerca de 3 años en sus cargos. Una parte de esta diferencia se explica en otros arreglos institucionales. Mientras los organismos que utilizan los dos primeros modelos de nombramiento contemplan un plazo definido para el ejercicio de sus cargos directivos, típicamente entre 6 y 8 años, los organismos que utilizan los dos últimos modelos de nombramiento establecen un mandato indefinido. La existencia formal de un plazo, junto con los mecanismos de freno y contrapeso revisados anteriormente, pareciera aumentar el tiempo

este resultado dentro de una distribución normal es inferior al 5\%. En la tabla 1, ello se ilustra incluyendo una o más estrellas en el superíndice izquierdo del resultado.

69 Todas estas diferencias quedan recogidas en algunas de las preguntas estructuradas que se compilan dentro del índice. PARDOw, D., supra nota 36. 
de permanencia de los funcionarios directivos y contribuir a la estabilidad de la autoridad reguladora. Desde esta perspectiva, la primera de nuestras expectativas respecto de las consecuencias asociadas al mecanismo de confirmación ante el Senado pareciera razonablemente satisfecha por la práctica administrativa en Chile.

Enseguida, nuestras expectativas iniciales también incluían que los candidatos, sujetos a confirmación por el Senado o designados bajo el modelo delegado, tuvieran menores niveles de afiliación política, mayor experiencia fuera del sector público, y mejores antecedentes profesionales. Respecto de este conjunto de expectativas, los antecedentes biográficos de los funcionarios directivos muestran resultados bastante menos claros. Por una parte, los candidatos nombrados a través del modelo discrecional tienen un índice de afiliación política similar que los candidatos sujetos a confirmación por parte del Senado ${ }^{70}$. Además, aunque en los otros dos modelos de nombramiento estos índices efectivamente disminuyen, ninguna de estas variaciones resulta estadísticamente significativa. Esto sugiere que el mecanismo de confirmación ante el Senado es relativamente poco efectivo a la hora de prevenir lo que Bauer y Ege denominan politización directa ${ }^{71}$, esto es, que el gobierno elija candidatos identificados con su propia coalición.

Por otra parte, el gobierno también puede utilizar los nombramientos como un mecanismo de recompensa, típicamente para premiar la lealtad previa de una autoridad reguladora, o bien castigar a los funcionarios directivos que actúan en contra de sus intereses políticos. Esta otra dinámica de poder es lo que los mismos Bauer y Ege conceptualizan como politización funcional $^{72}$. Al revisar la ocupación previa de los funcionarios directivos en Chile, constatamos que el sector público constituye el principal espacio de reclutamiento para la mayoría de las autoridades designadas bajo los modelos de nombramiento examinados, incluyendo el modelo de confirmación ante el Senado $^{73}$. La excepción estaría constituida por el modelo delegado, donde la

70 Siguiendo una metodología similar a la de Ennser-Jedenastik, citado más arriba, este índice es el resultado de un conjunto de preguntas estructuradas acerca de la posible militancia en partidos políticos, así como la participación en elecciones, cargos de confianza exclusiva o centros de estudios. Las respuestas están diseñadas para variar entre cero y uno, por lo que el promedio simple permite reflejar la intensidad de la afiliación política en términos absolutos, esto es, sin identificar a las personas dentro un eje valorativo como izquierda-derecha o liberalconservador.

71 BAUER, MW., y EgE, J., supra nota 36.

72 BAUER, MW., y EGE, J., supra nota 36.

73 El nivel de dedicación se estima evaluando las ocupaciones laborales de los funcionarios directivos durante los cinco años anteriores al nombramiento, incluyendo tanto ocupaciones de tiempo completo como de tiempo parcial. Se consideran como parte del sector público todos aquellos organismos que pertenecen a cualquiera de los tres poderes del Estado, con excepción de las universidades estatales. De la misma manera, se consideran como parte del sector privado todas las empresas y organizaciones gubernamentales privadas, con excepción nuevamente 
proporción de candidatos que se desempeñaban como funcionarios públicos es significativamente baja, y la proporción de candidatos que se desempeñaba como profesores universitarios es significativamente alta. Esta tendencia a seleccionar candidatos sin una carrera funcionaria previa puede interpretarse como un indicio de mayor independencia, especialmente debido a la magnitud de la diferencia con los promedios sobre ocupación previa para los otros tres modelos de nombramiento.

Por otra parte, los candidatos sujetos a confirmación ante el Senado muestran credenciales profesionales significativamente mejores a las del resto. Con todo, es importante tener en cuenta algunos aspectos metodológicos acerca de este índice sobre calidad profesional. De manera similar a Bach y $\mathrm{Veit}^{74}$, el índice se construye compilando información respecto de la tenencia de títulos profesionales y estudios de postgrado, así como del ranking de las distintas universidades donde se habría formado el candidato. En términos generales, un $95 \%$ de los funcionarios directivos nombrados entre 1990 y 2016 son abogados, economistas o ingenieros ${ }^{75}$. De las tres profesiones más frecuentes, sin embargo, ingeniería y economía tienen una tradición de internacionalización que lleva varias décadas. En contraste, la realización de posgrados es un fenómeno relativamente reciente para los abogados. Debido a que el Banco Central y la Comisión de Mercados Financieros representan cerca de un $70 \%$ de los nombramientos sujetos a confirmación ante el Senado, una parte de los mejores resultados en términos del índice de calidad profesional obedece a la mayor presencia de ingenieros y economistas en la dirección de estos dos reguladores financieros.

Finalmente, enfoquémonos en la estabilidad frente a cambios de gobierno. Como señala Lewis, uno de los elementos clave para asegurar la independencia institucional de las autoridades reguladoras, consiste en evitar que sus cambios de personal sigan el ciclo electoral y respondan a los intereses contingentes del gobierno ${ }^{76}$. Desde esta perspectiva, un buen indicio de mayor independencia y estabilidad en las agencias reguladoras chilenas, sería que sus funcionarios directivos continúen más allá del periodo presidencial en que fueron nombrados. A continuación, describimos y analizamos la manera de construir este parámetro de comparación: La Figura 1 muestra una estimación de la probabilidad de mantenerse en el cargo para cada uno de

de las universidades. Una descripción detallada de la metodología para esta estimación puede encontrarse en PARDOW, D., supra nota 36.

74 BACH, T., y VeIT, S., supra nota 35.

75 Respecto de la institución educacional de procedencia, la Universidad de Chile concentra bastante más de la mitad de los datos y la Universidad Católica de Chile cerca de otro tercio. En conjunto, ambas universidades representan un $85 \%$ de los nombramientos. Ningún otro plantel académico supera el 5\% del total. Además, un $44 \%$ de los funcionarios directivos tenía estudios de magíster al momento de su nombramiento, y otro $23 \%$ tenía estudios de doctorado.

76 LewIs, D., supra nota 22. 
nuestros distintos modelos de nombramiento. Siguiendo a Ennser-Jedenastik ${ }^{77}$, se utilizan las fechas de nombramiento y cesación de los funcionarios para identificar aquellos que seguían ejerciendo sus funciones luego de transcurridos 3 meses desde la instalación de un nuevo gobierno. Cada uno de los puntos corresponde al promedio de funcionarios directivos que efectivamente se mantuvo en su cargo después del plazo señalado, mientras que las barras verticales corresponden a intervalos de confianza estimados a través de una regresión logística. Al igual que con los días de duración evaluados en la sección anterior, las diferencias entre los distintos modelos de nombramiento son significativas.

FIGURA 1: PROBABILIDAD DE MANTENERSE EN EL CARGO PARA

CADA MODELO DE NOMBRAMIENTO

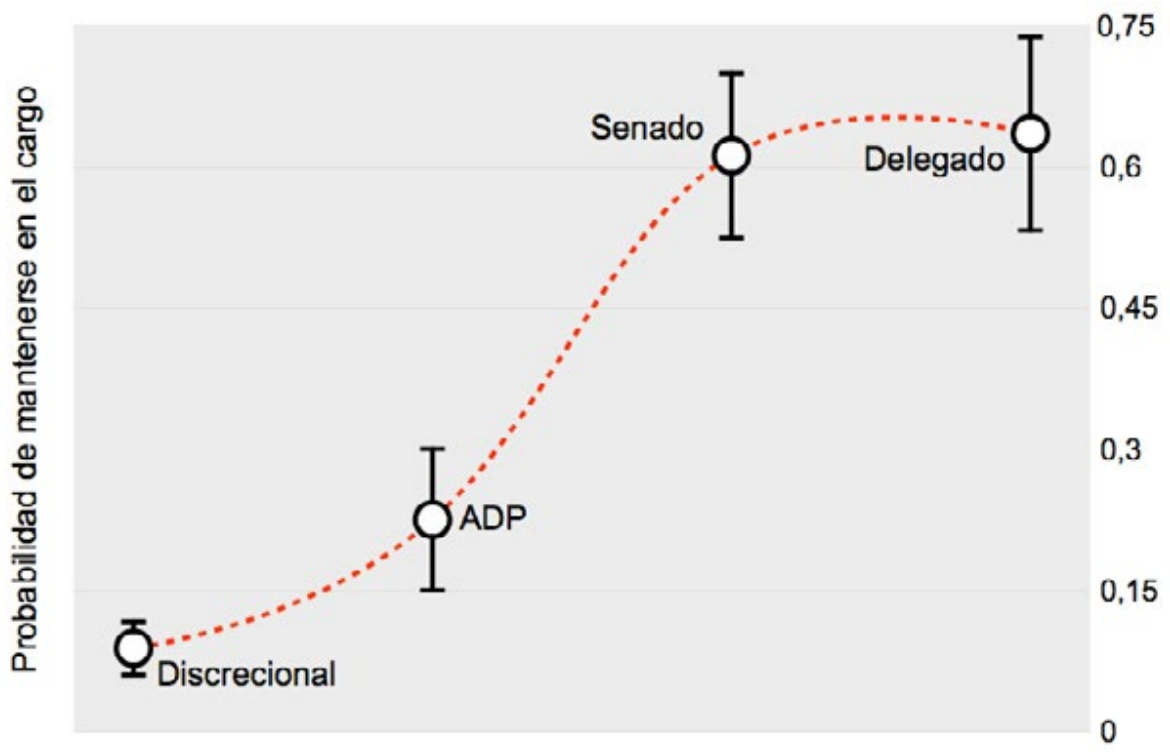

Fuente: elaboración propia sobre la base de información pública sistematizada para este trabajo

Un primer aspecto interesante a resaltar, es que solamente un $9 \%$ de los funcionarios nombrados conforme al modelo discrecional sobrevivieron a un cambio de gobierno, teniendo además un intervalo de confianza relativamente pequeño que varía entre un $6 \%$ y $12 \%$. Para apreciar la importancia de estos resultados, es importante tener en cuenta que gran parte de los nombramientos realizados a través del modelo discrecional ocurrieron entre 1990 y 2005. En Chile, este periodo de tiempo se caracteriza por una gran estabilidad en términos políticos: todos los presidentes pertenecían a la mis- 
ma coalición gobernante, mientras que sus programas de gobierno y equipos de trabajo en materias reguladoras eran bastante similares. No obstante, la fracción de funcionarios que permanecieron en sus cargos es baja. En este periodo se produjeron 75 nombramientos a través del modelo discrecional, pero solamente 4 funcionarios directivos mantuvieron su posición durante el gobierno siguiente ${ }^{78}$. Esto confirma que el modelo discrecional puede producir inestabilidad en los funcionarios, pese a la existencia de coaliciones políticas estables que continúan en el gobierno.

Ello contrasta con los nombramientos realizados a través del modelo ADP, donde cerca de un $23 \%$ de los funcionarios directivos sobrevive a un cambio de gobierno. El intervalo de confianza es también mayor, situando la probabilidad de mantenerse en el cargo entre un $15 \%$ y un $30 \%$. Además, la dimensión temporal funciona en el sentido contrario a lo que sucede con el modelo anterior. El sistema ADP empezó a funcionar el año 2003, implementándose progresivamente. Inicialmente, los nombramientos realizados con la participación del sistema de ADP eran menos de un quinto del total, mientras que actualmente esa proporción es cercana a los dos tercios. De esta manera, la mayor cantidad de los nombramientos a través del sistema ADP ocurre durante los últimos 4 periodos presidenciales. Este otro período de tiempo tiene como principal característica la alternancia en el poder entre coaliciones de centro-izquierda y centro-derecha. Por lo tanto, aunque el aumento en nuestra probabilidad de sobrevivencia es relativamente pequeño, también hay que considerar que los cambios de gobierno pasaron a significar transiciones mucho más intensas en materias de política reguladora. Así, por ejemplo, la posición del gobierno de Bachelet en materia de impuestos o pensiones divergía sustancialmente de la posición del gobierno de Piñera en esas mismas materias. Desde esta perspectiva, el aumento en la estabilidad de la dirección de las agencias por parte del modelo ADP, tiene que apreciarse a la luz de cambios significativos en los programas políticos de los gobiernos correspondientes.

Tratándose de los nombramientos sujetos a confirmación por parte del Senado, así como con aquellos realizados a través del modelo delegado, las diferencias con los resultados anteriores son importantes. En primer lugar, el porcentaje de funcionarios directivos que se mantiene en sus cargos después de la instalación de un nuevo gobierno es cerca de tres veces más alto, excediendo el $60 \%$. Consecuentemente, la probabilidad estimada de supervivencia

78 El caso más claro es el de Javier Etcheberry, quien ejerció como Director del Servicio de Impuestos Internos durante más de una década y sobrevivió a dos cambios de gobierno sucesivos (Aylwin-Frei, Frei-Lagos). Los otros tres funcionarios que se mantuvieron en sus cargos corresponden a Eugenio Celedón en la Superintendencia de Servicios Sanitarios, José Guzmán en la Superintendencia de Bancos e Instituciones Financieras y Benjamín Prado en el Servicio Nacional de Aduanas. Al igual que con el primer caso, los tres fueron nombrados durante la presidencia de Aylwin y se mantuvieron en sus cargos durante buena parte del gobierno de Frei. 
oscila en un intervalo de entre $50 \%$ y $70 \%$. Más aún, la utilización de ambos modelos de nombramiento va en aumento debido a que buena parte de los organismos creados desde la admisión de Chile a la OCDE recurren a este tipo de diseño institucional. Este es el caso del Consejo para la Transparencia, del Tribunal de Defensa de la Libre Competencia, y más recientemente, de la Comisión de Mercados Financieros. Es importante destacar, finalmente, que los niveles de permanencia en el cargo son similares, tanto para el modelo delegado como para el modelo de confirmación ante el Senado.

\section{CONCLUSIONES}

Este trabajo sistematiza los distintos modelos de nombramiento de las agencias reguladoras independientes en Chile, aportando evidencia y proponiendo elementos para el debate sobre la autonomía institucional que actualmente se lleva a cabo en Latinoamérica. Chile, al igual que varios países de la región, tiene diversos sistemas de nombramientos que operan en un contexto de presidencialismo fuerte.

Desde esta perspectiva, nuestro artículo compara los nombramientos directivos de autoridades reguladoras donde el Senado aprobó los nombramientos realizados por el Presidente de la República, con aquellos modelos donde el Presidente nombró a dicho directivo de manera discrecional o a través del sistema de Alta Dirección Pública. Analizando cerca de 200 nombramientos realizados en Chile entre 1990 y 2016, encontramos que los directivos elegidos con participación del Senado tienen mejores antecedentes profesionales y vienen con mayor frecuencia desde fuera del sector público. Nuestra evidencia también muestra que el tiempo de permanencia de los directivos nombrados con participación del Senado es dos veces más largo, mientras que es cerca de tres veces más probable que se mantengan en sus cargos después de la instalación de un nuevo gobierno. Todas estas circunstancias evidencian un grado de conexión significativo entre la independencia formal y material de nuestras agencias reguladoras, así como también la importancia del Senado en el sistema de frenos y contrapesos para los nombramientos directivos. Por su parte, los efectos del sistema ADP parecieran limitarse a reducir levemente el nivel de afiliación política de los directivos y aumentar también levemente la estabilidad en el cargo. Con todo, los efectos del sistema ADP van bastante más allá de los niveles directivos, limitando la discrecionalidad en los nombramientos en un conjunto de funcionarios intermedios cuyo estudio escapa a los límites de este trabajo. En este sentido, nuestros resultados deben verse mucho más como un respaldo a los efectos positivos del proceso de confirmación ante el Senado, antes que como una crítica al sistema ADP.

En términos generales, estos resultados son significativos para la discusión sobre qué modelos institucionales utilizar a la hora de designar a las autoridades superiores de agencias reguladoras, especialmente cuando buscamos 
fortalecer su autonomía. Esta es una discusión crucial para todos los países de la región que han iniciado procesos de reforma institucional destinados a incorporarse a organismos internacionales con mayores estándares de calidad reguladora. Aunque hay varias limitaciones en nuestro estudio, los datos que ofrecemos corroboran parte de las expectativas que la literatura latinoamericana viene sosteniendo desde el inicio de los procesos de privatización a finales del siglo pasado. Ellos confirman que la existencia de modelos institucionales distintos es relevante, y que los esfuerzos por sistematizarlos permiten identificar resultados heterogéneos. Esta heterogeneidad de resultados, por su parte, es importante a la hora de ilustrar la conexión que existe entre los distintos modelos institucionales, la idoneidad técnica de sus cuadros directivos y la intensidad de su afiliación política. Ahora bien, este estudio es solamente el punto de partida. Nuestra investigación debe complementarse con el análisis de otros factores relevantes para entender de mejor manera el impacto de los distintos diseños institucionales en el comportamiento de los reguladores. A la luz de nuestro trabajo, el siguiente paso pareciera ser encontrar una manera de comparar el desempeño entre modelos donde varios directivos son nombrados simultáneamente y podrían ser objeto de negociaciones entre las coaliciones políticas, con aquellos donde solamente se evalúa un directivo a la vez.

\section{REFERENCIAS}

Aghion, P. y Tirole, J. Formal and real authority in organizations. Journal of Political Economy, 1997, Vol. 105(1), 1-29.

AgüEro, F. y Montt, S. Chile. The Competition Law System and the Country's Norms. En: Fox, E. y Trebilcock, M. (eds.) The Design of Competition Law Institutions: Global Norms, Local Choices. Oxford University Press, 2013, 149-193.

Aninat, C. Balance de Poderes Legislativos en Chile. ¿Presidencialismo Exagerado o Base de un Sistema Político Cooperativo? Política, Vol. 47, 2006: 127-148.

Bach, T., Hammerschmid, G., y Löffle, L. More delegation, more political control? Politicization of senior-level appointments in 18 European countries. Public Policy and Administration: 0952076718776356. 2015.

Bach, T., y Veit, S. The Determinants of Promotion to High Public Office in Germany: Partisan Loyalty, Political Craft, or Managerial Competencies? Journal of Public Administration Research and Theory, Vol. 28, n. ${ }^{\circ}$ 2, 2017: 254-269.

Bassa Mercado, J. El Tribunal Constitucional en la Constitución Chilena Vigente. En: Bassa Mercado, J., Ferrada Bórquez, J. y Viera Álvarez, C. (eds.). La Constitución Chilena. Una Revisión Crítica a Su Práctica Política. Santiago: Lom, 2015, 253-84.

Bauer, MW., y Ege, J. Politicization within the European Commission's bureaucracy. International Review of Administrative Sciences, Vol. 78, n. ${ }^{\circ} 3,2012$ : 403-424. 
BAWn, K. Political control versus expertise: Congressional choices about administrative procedures. American Political Science Review, Vol. LXXXIX, n. ${ }^{\circ}$ 1, 1995: 62-73.

Bendor, J. y Meirowitz, A. Spatial models of delegation. American Political Science Review, Vol. 98(2), 2004, 293-310.

Bronfman, A., Cordero, E., y Aldunate, E. Derecho Parlamentario Chileno. Funciones y Atribuciones del Congreso Nacional. Santiago: Legal Publishing - Thomson Reuters, 2013.

Camacho Cepeda, G. La problemática de la potestad normativa de las superintendencias. Actas XXXIV Jornadas de Derecho Público, 2004, 423-32.

Carey, J. Parties, Coalitions, and the Chilean Congress in the 1990's. En Morgenstern, S. y NACIF, B. (eds.). Legislative Politics in Latin America. Cambridge University Press, 2002, 222-53.

CARMONA, C. Una aproximación general sobre las superintendencias desde la perspectiva del Derecho. Santiago, en consulta con el autor, 2005.

Cea Egaña, J. Derecho Constitucional Chileno. Vol. III. Santiago: Ediciones Uc. 2013.

Cordero Vega, L., y García, J. Elementos para la Discusión sobre Agencias Independientes en Chile. El Caso de las Superintendencias. Anuario de Derecho Público, 2012, 415-35.

Costa, R., y Waissbluth, M. Tres años del Sistema de Alta Dirección Pública en Chile: balances y perspectivas. Documento de Trabajo, Serie Gestión, n. ${ }^{\circ}$ 94. Santiago de Chile: Control de Gestión (CEGES), Departamento de Ingeniería Industrial, Universidad de Chile, 2007.

Cutler, L., and Johnson, D. Regulation and the Political Process. Yale Law Journal 84, 1974: 1395.

Díaz de VAldés J., J. Anomalías Constitucionales de Las Superintendencias: un Diagnóstico. Estudios Constitucionales, Vol. 8, n. ${ }^{\circ}$ 1, 2010: 249-82.

Ensalaco, M. In with the New, Out with the Old? The Democratising Impact of Constitutional Reform in Chile. Journal of Latin American Studies, Vol. 26, n. ${ }^{\circ}$ 2, 1994: 409-29.

Ennser-Jedenastik, L. The Politicization of Regulatory Agencies: Between Partisan Influence and Formal Independence. Journal of Public Administration Research and Theory, 2016, 507-518.

Enteiche Rosales, N. Superintendencias: una necesaria autonomía constitucional. En Alvear, J. y Covarnubias, I. (eds.). Desafíos Constitucionales. Propiedad, Debido Proceso, Libertad Religiosa, Régimen Político y Administrativo. Valencia: Tirant lo Blanch, 2017.

García, G. J. ¿Inflación de superintendencias? Un diagnóstico crítico desde el derecho regulatorio. Actualidad Jurídica, Vol. 19, 2009: 327-72.

García, G. J. Ni Césares, Ni Caudillos, Ni Redentores: el fin del hiperpresidencialismo chileno. En García García, J. (ed.). ¿Nueva Constitución o Reforma? Nuestra Propuesta: Evolución Constitucional. Santiago: Thomson Reuters, 2014, 351-76. 
García G., J., y Verdugo R., S. De las superintendencias a las agencias regulatorias independientes en Chile: Aspectos constitucionales y de diseño regulatorio. Actualidad Jurídica, Vol. 22, 2010: 263-305.

GILARDI, F. Policy credibility and delegation to independent regulatory agencies: a comparative empirical analysis. Journal of European Public Policy, 2002, Vol. IX, n. 9 (6), 873-893.

González-Bustamante, B., Olivares, A., Abarca, P., y Molina, E. Servicio civil en Chile, análisis de los directivos de primer nivel jerárquico (2003-13). Revista de Administração Pública, Vol. L, n. ${ }^{\circ}$ 50, 2016: 59-79.

González-Bustamante, B. Civil service models in Latin America. En Farazmand, A. (Ed.) Global encyclopedia of public administration, public policy, and governance. Cham: Springer International Publishing, 2018, 1-9.

Guasch, J., y Spiller, P. Managing the regulatory process: design, concepts, issues, and the Latin America and Caribbean story. The World Bank, 1999.

GutiérRez, LH. Regulatory Governance in the Latin American Telecommunications Sector. Utilities Policy, Vol. 11, 2003: 225-240.

Hube, C. Hacia un presidencialismo moderado: más herramientas legislativas y de control para el Congreso. En García García, J. (ed.). ¿Nueva Constitución o Reforma? Nuestra propuesta: evolución constitucional. Santiago: Thomson Reuters. 2014, 377-92.

JoRdana, J., y Ramió, C. Delegation, Presidential Regimes, and Latin American Regulatory Agencies. Journal of Politics in Latin America, Vol. 2, n. ${ }^{\circ}$ 1, 2010: 3-30.

Kydland, F. y Prescott, E. Rules rather than discretion: The inconsistency of optimal plans. The Journal of Political Economy, 1977, 473-491.

KIEwiet, DR., y McCubbins, MD. The logic of delegation. Chicago, University of Chicago Press. 1991.

Krause, GA., y O'ConNELl, A. Experiential learning and presidential management of the us federal bureaucracy: Logic and evidence from agency leadership appointments. American Journal of Political Science, Vol. 60, n. ${ }^{\circ} 4,2016$ : 914-931.

Larraín, G., y Larraín, M. Hacia Una Reforma de La Institucionalidad Financiera en Chile. Documento de Trabajo, Universidad Del Desarrollo 12, 2010.

Levy, B., y Spiller, P. Regulations, Institutions and Commitment. New York, Cambridge University Press, 1996.

Lewis, D. Presidents and the politics of agency design: Political insulation in the United States government bureaucracy. California: Stanford University Press, 2004.

LewIs, D. The politics of presidential appointments: Political control and bureaucratic performance. Nueva York: Princeton University Press, 2010.

Londregan, J. Appointment, Reelection, and Autonomy in the Senate of Chile. En Morgenstern, S. y Nacif, B. (eds.). Legislative Politics in Latin America. Cambridge University Press, 2002, 341-76. 
Majone, G. Nonmajoritarian institutions and the limits of democratic governance: a political transaction-cost approach. Journal of Institutional and Theoretical Economics, Vol. CLVII, 2001: 57-78.

Martínez-Gallardo C, Murillo MV Agency under Constraint: Ideological Preferences and the Politics of Electricity Regulation in Latin America. Regulation \& Governance, 5, 2011: 350-367.

McCarty, N. The Appointments Dilemma. American Journal of Political Science, Vol. 48, No. 3, 2004: 413-428.

Montes, E., y Vial, T. The Constitution-Building Process in Chile: The Authoritarian Roots of a Stable Democracy. Stockholm: International IDEA, 2005.

Montoya MA., y Trillas, F. The Measurement of the Independence of Telecommunications Regulatory Agencies in Latin America and the Caribbean. Utilities Policy, 15, 2007: 182-190.

Moran, M. The British regulatory state: high modernism and hyper-innovation. Nueva York, Oxford University Press, 2003.

Navia, P. Living in Actually Existing Democracies: Democracy to the Extent Possible in Chile. Latin American Research Review. Vol. 45, special issue, 2010: 298-328.

Pardow, D. El Servicio Nacional del Consumidor de Chile (Sernac) y los reguladores sectoriales: buscando mecanismos para una mejor coordinación. Economía y Política, Vol. 2, n. ${ }^{\circ}$ 2, 2015: 107-136.

PARDOW, D. ¿Control o autonomía?: El debate sobre agencias regulatorias independientes, 2017 (inédito en consulta con autor).

Pardow, D. ¿Técnicos o políticos?: Radiografía del Sistema de Nombramiento de Directivos en Agencias Regulatorias Independientes, 2018 (inédito en consulta con autor).

Pavón Mediano, A. Agencies' formal independence and credible commitment in the Latin American regulatory state: A comparative analysis of 8 countries and 13 sectors. Regulation \& Governance, 2018.

Pfeffer, E. Reformas Constitucionales 2005. Santiago: Editorial Jurídica de Chile, 2005.

Pfeffer, E. Manual de derecho constitucional. Vol. 2. Ediar Conosur, 1990.

RaJevic, E. "El Consejo para la Transparencia Como ‘Administración Independiente. En Transparencia en la Administración Pública. Santiago: Legal Publishing, 2010, 231-47.

Ríos, L. La generación del Tribunal Constitucional. En Nogueira Alcalá, H. (ed.) Jurisdicción constitucional. En Chile y América Latina: Presente y Prospectiva. Santiago: Universidad de Talca - Lexis Nexis, 2005, 451-66.

Sierra, L. (ed.). Diálogos constitucionales. Santiago: Centro de Estudios Públicos, 2015.

Silva, A. Tratado de derecho constitucional. Vol. VI. Santiago: Editorial Jurídica de Chile, 2000. 
Soto, S. Propuesta Inicial Sobre Forma Del Estado. En Sierra, L. (ed.) Propuestas Constitucionales. Centro de Estudios Públicos, 2016, 87-106.

Sото, S. Relaciones entre el Congreso Nacional y el Poder Judicial: La Importancia de la Apertura. Ius et Praxis, Vol. 13, n. ${ }^{\circ}$ 1, 2007: 135-166.

Stephenson, M. Optimal Political Control of the Bureaucracy. Michigan Law Review, 2008, 53-110.

TAPIA, J., y CORdero, L. La revisión judicial de las decisiones regulatorias: Una mirada institucional. Estudios Públicos, 139, 2015: 7-66.

Trillas F, Montoya MA. Commitment and Regulatory Independence in Practice in Latin American and Caribbean Countries. Competition and Regulation in Network Industries, 12, 2011: 27-56.

Tucker, P. Unelected Power: The Quest for Legitimacy in Central Banking and the Regulatory State. Princeton University Press, 2018.

Vergara, A. El Contencioso Administrativo en Materia Eléctrica: Naturaleza jurisdiccional de las funciones del Panel de Expertos. Revista de Derecho de la Universidad Finis Terrae, Vol. IX, 2005: 207-229.

Vergara, A. Autoridades administrativas independientes (agencias): Mito y realidad de un modelo conveniente para Chile. Revista de Derecho Administrativo Económico, Vol. XXV, 2018: 45-58.

Wilson, J. Bureaucracy: What government agencies do and why they do it. New York, Basic Books, 1989.

Wood, D. y Bотнe, J. Political transaction costs and the politics of administrative design. Journal of Politics, Vol. LXVI, n. ${ }^{\circ}$ 1, 2004: 176-202.

Zárate, S. Hacia un Estatuto Constitucional de Órganos Autónomos. En García García, J. (ed.). ¿Nueva constitución o reforma? Nuestra propuesta: evolución constitucional. Santiago: Thomson Reuters, 2014, 491-525. 